\title{
ABDALLAH HAMmadi
}

\section{CONVERSO CON EL OLVIDO \\ (Poemas)}

Edición de

Isaac Donoso

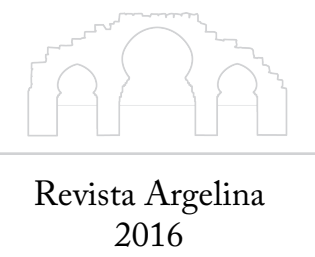



Converso con El Olvido

¡El temporal de la soledad muerde el vacío de tu horizonte! $\mathrm{Y}$ una frescura de arco iris cae en pesadillas en tu lecho nocturno.

¡Lejos de viento quedó tu arenal sin navío.

¡Qué sorbo de aroma te alivia!

¿Qué grito fantasmal se ve urgir entre las ventanas de tu abismo! Lueña se marchó, aquella brisa de tu mañana.

Amo con la fuerza del azor el azul celestial que se derrama de las lenguas de tu alborada.

¡Oh sonrisa, fúnebre y polvorienta, no te acerques a su dolor con tu placer de cuchillo!

\section{II}

El viento del sur lamenta esta noche.

Le vi arrascar el opaco mirador de un corazón perdido.

Suele esparcir frescor de recuerdos: 
suele acariciar labios sedientos

de tu ventana:

suele vender con ternura aquella frente.

El viento de esta noche

con pesadilla de cristal se rompe

en tu pecho.

\section{III}

Late corazón... No todo

se lo ha tragado la tierra.

A. Machado

Un olor de malestar cubre la cal de mi estancia, y un hálito de suspiros verdes marcados por fenazos de estupor desvelado, tendido al borde de una almohada. Una silueta fugaz con hullas grises se quedó tejida en un pensamiento. Ya ves la noche, amarrada en su atarazana con las estrellas del recuerdo.

¡No gira el espacio esta noche, se ve contoneando, vacilando y vuelve a recaer en tu regazo como pesadillas desérticas! Todo huele a fervor de dunas. ¿No sé qué? ¡Tal vez a senderos torcidos con cristales de espejismos rotos en una garganta sediente!

Dejé la frente al alcance de la brisa del atardecer...

Dejé los brazos hundir en los rayos teñidos del ser y del estar... 
Nada trajo al pájaro dorado de aquella isla de miradas solitarias.

Sigue mordiendo el capricho una vaga visión brumosa desatada.

Tal vez, clara como un sorbo de un ojo de azor, sigue entretejida entre las uñas de un expatriada casida.

\section{IV}

...Me acerqué a su mirada

con el fin de recolectar

los narcisos de su pecho.

Cuerpo a cuerpo se lanzaron

disturbios en los labios,

y de golpe se vertió

un vaso lamiendo el suelo.

¡En el acto vi naufragar los narcisos

en la clara oscuridad!

\section{V}

\section{FEDERICO}

VOCES TE RECLAMAN DESDE LAS ALTURAS DEL ATLAS

Aquí me tienes ante estos ojos tuyos que hicieron crecer a la morena aceituna. Aquí estoy, empapado con sangre de la revolución y polvoriento de las arenas del lejano Sur. He sido enviado, sin más presentes 
que una flor lírica de palpitar beduino, una cabalgadura beréber

para la que todas las distancias son estrechas, y una azucena árabe de pétalos marchitos.

Ay hermano, ay hijo de mi madre, que nuestra sangre tiene ya sus frutas maduras en las alturas de ese Atlas que se extiende bajo este horizonte, que las balas de la O.A.S. no son ya más que una extraña melodía que suena en nuestros trigales verdes. Esos mártires nuestros que cayeron en los barrancos se han convertido en una fragancia silvestre que llena de júbilo los astros del cielo. Hermano, tu que eres hijo de esa madre nuestra que es una lírica beduina.

He venido de los picos del Aures, enviado con la carga de ese pueblo que ha sembrado en cada surco un grano de revolución.

¡Ay hermano Federico!

Que he venido para sacudir de tu frente el polvo del olvido para sembrar sobre tu losa una flor cuyo nombre es al-Andalus. Hermano, que hoy vengo para llevarme la ceniza de tus huesos y quemarla como incienso en el templo de nuestra liberación sagrada.

Voy a llevarte a mi pueblo, hermano, 
a ese pueblo que ha hecho nacer el sol en medio de la oscuridad nocturna. Voy a llevarte a mi tierra, ésta que supo enseñar al enemigo el modo de inclinarse

ante los brazos robustos del pobre.

Voy a llevarte, en fin, hacia la lejanía, bajo aquella palmera orgullosa, junto a aquel pozo de agua de cristal Y sobre la alfombra dorada del desierto, voy a edificar el templo de tu culto, que será construido con los laureles de la poesía beduina.

Levántate pues, hermano, y mira hacia el Sur que flota en espejismos.

Verás allí una silueta que destaca entre las dunas del hogar.

Es la imagen de alguien que espera anhelante, vamos, ven conmigo, para que nuestra tierra de libertad celebre tu llegada.

\section{VI}

\section{A MACHADO}

¿Hiere tu corazón la luz de la luna ensangrentando la noche tus párpados en vela?

¿Te sumerges en el aire como la niñez perdida a jirones en las haces 
del gentío?

¿Gritas buscando dónde está Dios, siendo tú Dios amado del hombre?

¿Soplas, soplas como la tormenta?

¿Hierves, hierves como el ojo de la bruma?

$¿ A b r e s$ al viento tus ventanas

mirando a la aurora

de mañana:

y en una barca de fantasía infantil

abandonas las esperanzas, soñolientas

como la victoria?

¿Anhelas la plaza vacía?

¿Y la fronda verde floreciente

y el sol en el crepúsculo rojo

y la luz que se entierra

pese al destino?

¿Por qué, hijo del sol meridional,

hiciste de la vida una nota

de guitarra?

\section{VII}

Tu imagen detrás de un cristal de despedida

me persigue,

hasta alcanzar el fondo del mismísimo

sentimiento.

Era tenue, borrosa, lejana

pero en el fondo del espejo se declina

como un planear de una gaviota

sin marinero. 
Sigue, y me persigue palpitando

con un adiós sin promesas

$\mathrm{y}$ sin silencio.

Arde corazón, gime suspiro

la tarde lluviosa y el cantar

a tu alcance.

Lejano quedó tu cristal:

oh mundo de aquella tarde.

Todo se fue tras un cristal

alejándose con el recuerdo de una mano

y con la despedida en la otra...

¿Adónde va tu camino caminante?

Una silueta fugaz te la robó

una vaga tarde de llovizna

casi de invierno

mientras una espina de pasión

se clava en el ocaso...

\section{VIII}

A mi amigo Juan de Loxa

La tormenta de ayer me parece

una flor lejana que se escapó

del exilio de aquella primavera

¿Recuerdas...?

¡Ya sentí que sólo fueron palabras

reflejando conceptos torturados

con fulgor de una oscuridad

verídica por encima del espacio!

Son palabras que nos relatan palabras

rojizas como espumas o plumajes 
regados por las últimas gotas

de un polvo del mediodía.

Palabras quemadas de un sol infernal

que de tanta transparencia se ven oscuras

por herencia.

Como una mesa cargada: pero no sé

de qué puede ser cargada... tal vez

de pánico.

La palabra se siente famélica, por eso

muerde el espacio.

El espacio se esconde tras un cielo de claridad

y se refleja al borde de una carretera

de rayos...

Oscura, clara transcurrió la palabra

ahorcada antes de nacer frente

del espacio.

Qué claridad nocturna se ve fundir

con ojos lánguidos, cristalinos, tenebrosos

y aromáticos.

Al borde de la rivera una clara

palabra atada al tronco del espacio.

\section{IX}

Ve y despierta al copero que parece dormido: ya el relámpago al ámbar oloroso ha encendido. Ven, escánciame y bebe este fragante vino, No bay delicia en el mundo como su cara hermosa y la copa!

lbn Játima de Almería, s. XIV

Pensé que sigues esperando 
tras el velo con tus ojos de hurí

la llegada del Halcón de Qurays.

Ya es tarde, muchacha

Katy ha denunciado tu velo.

Sal de tus follajes con tu vaquero

de gringo.

¡El Zoco del viernes dejó

de hervir desde el año del "catapún"...!

¡La túnica de tu amante

en una jaula cristalina

respira un aroma de peste

de un dólar californiano!

\section{X}

Galopando, sobre una montura

de un espacio sin vestido

sobre una crin fugaz de un

viento llamado caballo.

Nada impide el paso

una palmera altiva mirando

al cielo sin hacerme caso.

Un buen jorobado

entretenido con el ocaso.

Todo como lo ves gira en torno

del espacio

nadie, con su hacha negra

impide las ceremonias míticas

del Siroco.

¡Así vuelvo a nacer cada día

con mi montura y mi viento! 


\section{XI}

Tengo frío mujer de mis

quimeras,

tengo sed, ninfa del

norte...

¡Ya, me encuentro vacío

sólo, con mi recuerdo

y mi desierto!

Además, la madre virgen

de la "Lírica" espesura cerró

sus puertas a mi pecho.

¡Qué lástima!

...aún pido un trago

de suerte...

Abre hacia el calor tu ventana;

traigo del lejano arenal

una flor de canto.

\section{XII}

\section{¿No VOLVERÁ NeRUDA?}

No volverá. No.

No volverán a escribirse los versos más tristes ni de nuevo titilarán los astros en la Onda azul infinita.

No volverá...

$\mathrm{Ni}$ girarán los vientos desnudos en la noche para abofetear las contraventanas cerradas.

No volverá. 
Y ya no se pedirá el castigo de las serpientes y de las hienas voraces.

No volverá...

y no se verá la noche inmensa sin la amada.

No volverá

para cubrirla, como la primavera

cubre a los cerezos.

Y no caerán los versos, como el rocío sobre el pasto,

encima del corazón huérfano

bajo las tinieblas de penumbra.

¿Quién infundirá paciencia

a la tierra y a los indios?

$¡ A$ Ah, montes de Chile, alturas de Macchu Picchu, ardientes hombros de $\mathrm{Cuba}$ encendidos hornos del cobre, remotos pueblos de España como luciérnagas en la noche oscura!

¿Quién levantará la melodía del verso, alimento eterno, hacia los corazones que laten en el bramido de ola roja arrasadora?

No volverá...; y no morirá...

Y no veremos el amor que sopla de los labios de Peleas y Melisenda.

No volverá el pan de los pobres ni se trillará la vida bajo los cascos de los caballos. 
¿Marchaste porque te llamara Lorca

desde los rayos del alba?

Cabalgaste en el hoyo del último sueño

besando a la muerte?

La piedra de la muerte no ensangrentará tus

pasos

infinitos.

He sabido del rayo de luz

que el relámpago de la letra resplandece

hasta el fin del mundo;

y he sabido del eco del crepusculario que una

estrella

en el sur dibujó el aliento

de tus entrañas angustiadas.

Y saltaste sobre el mar de la muerte

Y caíste en el cielo de la vida.

Cante tu dulce voz,

plenitud de todas las gargantas humanas:

duerma la gloria de vísceras degolladas

y huya el llanto

de la cárcel

de los ojos

carmesí

para siempre, para siempre

a los susurros,

a la noche que marchita los restos

de la vida. 


\section{XIII}

POEMA A MI MADRE

Palabra que no olvidaré, profunda como el mar con sabor de aire y gusto de amor en los labios.

La busqué en los collados de los códices antiguos, pero se escurre de mis manos como un pez de manos de un pescador.

Suave y lisa

la veo cercana junto a mí, frente a mis ojos saltones.

Y casi la toco y la vierto en mi copa

para beberla.

Y vuela con alas de pájaros gris

remontándose a lo alto

hasta desaparecer.

Resbaladiza, o di -si quieres-

bruma transparente

que se amontonó sobre mi pecho.

Habita en mi alma antigua y en la nueva, fluye en mis venas como la sangre (roja y blanca)

$\mathrm{y}$ ¿cómo no puede saber su contenido?

$\mathrm{Ah}$, dueño de la antorcha, con ella encendiste la luz violeta del sol. 


\section{XIV \\ Silencio HONDO DE GRANADA}

\section{A mi amigo Manuel Villar Gil}

El horizonte pálido se extiende

con su triste color

y sobre la alfombra verde galopa

el carro del tiempo

llevando los ídolos y las estatuas

y dejando tras si profundos carriles

sobre los grises rastrojos.

La ciudad blanca se alza con su pico erguido

y la colina roja despunta en un sol

que no conoce el ocaso,

en el abismo del océano.

Tiene días de mañana,

ignora las noches.

El tañido de la campana revuelve los

corazones

sedientos refugiados en las imágenes

para que los acune la esperanza

asomada a la orilla del infinito.

Un ángel de mirada faraónica,

de alas abatidas, hundida la cabeza

y el corazón roto en la cruz sangrienta.

Es el que se hundió en el mar,

sin retorno...

Ojalá mi verso fuera un sueño

frente a las preguntas del pasado, 
porque atónito no sé

si soy el amante o el extraño

en estos palacios.

Dolor de Granada dormida

¿Dónde está el bello perfume de la 'abayya

que arrastra su cola

y el turbante de puntas retorcidas

y la corona cristalina y brillante como el sol

en el degüel o del crepúsculo rosáceo?

¿Dónde están los potros, las cantoras, la corte?

¿Dónde están los Banu al-Ahmar?

Ay, pena de la partida antes de que llegase el extraño.

Pena de los palacios vacíos en los que se cerraron

hasta los párpados,

y la rosa que vigila sonriente

y el fragante jazmín y el narciso de pétalos abiertos

y marchito por la lejanía

en la estrechez del largo camino, dormido al amblar de los pasos.

Granada, aquí estoy abriendo mis brazos

ante tu gloria coronada de espinas

y, descalzo, piso tu esplendor

y me agota la humillación de épocas ya idas.

¿Dónde están tus tempestades y tus truenos?

¿Dónde está la inspiración bajada al universo?

¿Dónde las deliciosas fragancias

impregnadas del verdecer de los olivos

y del servo del Guadalquivir

que decapita con su daga

tu andaluza tierra dormida?

Ay, brisa ahogada con llanto de penas y 
dolores.

Partamos la desgracia y el pesar

bajo el cielo a quien encadenaron los años de miseria.

Aquí estoy, acurrucado, atormentado por el verbo

y el agente y la circunstancia y el adverbio

y la oposición a la luz de la luna

de equilibrio endeble.

¿Dónde está el relámpago, el chaparrón,

el león rugiente?

Quiebren las tormentas el vaso de mis penas

$\mathrm{y}$ agote los horizontes del sabor

de mi nostalgia.

Heme aquí, vivo sobre las trizas de la noche, expectante con su lámpara artificial.

Y tú, cantas en el Generalife, quejosa del sufrimiento lejano, tú que nadas en el alba del reino de la fantasía.

Despacio, cuenta la historia de la Alhambra, una canción.

Y si to corta la timidez, no to avergüences, porque en el silencio son dulces los susurros.

Aquí, envuelto en las ramas de los arboles, me atrapa el canto del agua con el murmullo de sus quejas.

Aquí estoy besando la frente del león de lomo hundido por el destino silente. Aquí, residuo de la bruma, espiral en el seno de Orión, errante, perdido. 
marinero sin nave, poeta al que el amor destrozó

los párpados sobre la guitarra.

No me preguntes cuando nos encontramos

tras el olvido.

Somas así:

vivimos y nos moriremos

pese a las campanas de la muerte.

Y quedaremos bajo el ala de la noche,

en sus tristes fulgores.

Enviamos el suspiro para verlo

como una lágrima que corre

en las mejillas del Darro.

\section{$\mathrm{XV}$ \\ A mi amigo Carmelo Sánchez Moros}

Cuando el agua susurra al oído de los guijarros, el céfiro se detiene cauteloso como espia;

pero un pájaro con su canto le delata, y el céfiro se atemoriza ante el escándalo.

Llora entonces una bruma procurando la sonrisa de las flores.

(Poeta granadino anónimo del siglo XV)

Por tu rostro sombrío

borraré las raíces del espacio.

Por tu agua gemida

me casaré con tu fragancia.

Por tus versos oriundos

sembraré mis arenas. 
Por tu muda sonrisa cabalgaré el viento

Por tu mirada marchita besaré mi alfanje.

Por tu trágica sin venganza

renuciaré a mi Sinhaya.

Por tus rosas del recuerdo

encarnaré a Abu-1-Hayyay.

Por tu sorda lejanía

resucitaré a Ibn al-Jatib.

Por tus torres brumosas

edificare mis casidas.

Con azucenas y zureo levantaré tu al-mibrab.

Con mi sudor de zinati

y mi yegua berberisca

alcanzaré tu Ben Omaya.

Regaré tus arriates, tu ámbar de Oriente

con el treno de mi laúd de mirto.

Por el vino y el copero.

Por el mancebo y la Zumaya.

Por Badis y el Bermejo.

Te haré ofrenda, mi Constantina.

\section{XVI}

Don QuIJOTE SE PONE EN CAMINO

Dedicado al gran poeta Vicente Aleixandre

¡Venga mi Rocinante!

el que suele rodar como un guijarro.

¡Venga mi rodela, mi espada y esa mi lanza 
tallada en colmillos de tigre de feroces junglas!

\section{iA mí!}

Pues que saldré a caminar, a derribar el molino ruidoso y arrancaré de raíz esos vientos que en mis oídos aúllan, que perturban el descanso de mi cementerio blanco,

la siesta bajo la frondosidad desnuda, el beso del azahar en mi marchita primavera, la siega de espigas en mis bancales yermos, el pasto de inútiles rastrojos, la noche, el día y esa llama de sol de helada crueldad.

¡Venid a mí!

y surcaré esa Castilla estéril que tal vez parirá un hijo con ala de pájaro, encendiendo, quizá, las velas de tu templo mortecino.

¡Venid a mí!

y abriré con la punta de mi lanza las venas de esta Mancha que perdió su último esposo.

¿No veis, acaso, cómo el luto marchita sus párpados?

¡Sancho, mi apoyo, mi compañero!

tú que eres parte de mí mismo, tú, mi propio camino, observa con atención y planea con oído lentamente:

Yo soy una bandada de pájaros

y con bandera blanca surco los campos. Soy una lanza de golpe fatal, 
cuya agilidad somete a las fieras.

Soy un buen nacido

que en la palestra te conquista la esperanza, Soy aquél que te ha contado las leyendas de Grecia

y quien pervivirá como las inscripciones en las ruinas antiguas.

Soy yo ese profeta enmascarado de selva, engendrado de la carne de la tierra.

Yo soy quien se arroja al mar

y te protege del furor de la tormenta.

Un bálsamo soy para la herida del pájaro, alguien a cuyo cuello se anuda la desgracia

y cuya ausencia es patente, cuando la tiniebla es rival de la verdad.

Con una luz rojiza voy en pos de un imposible preguntando a los hambrientos por el veneno de las sierpes.

Soy, en fin, esta miseria negra ansiosa de que salten los grilletes.

Ésta es mi rodela, Rocinante es mi caballo,

no es preciso que usurpe la yegua del testarudo $\mathrm{Cid}$

cuya mellada espada, es ya de inútil de tajo, y su Babieca rendido

¿No lo ves?

Está como un halcón acurrucado allá en Vivar y no consiente responder a mi reto.

¡Sancho, mi estandarte!

¡Sancho, mis sandalias!

Dejemos ya el descanso en estos aquilones.

$¿$ No ves, la brisa se entorpece con las alas del 
hambre?,

¿qué tiembla entre las uñas del águila?

Las moscas crueles, coma un reloj en las senos del tiempo van contando sus vertebras. ¡A mí, Sancho! ¡A mí, compañero!

Disponte ya, pues que hoy serás mi escudo, mi arnés, mi ejército.

Serás hay mi polvo y mi bonanza y mi nube

y esos labios míos conscientes bajo la luz de la luna.

Caminaremos con el viento dejando los ritos

bajo los cascos de nuestra gloria, devolviendo así a la noche su peregrino sol,

y libertad al mar que preso está de península,

que las cadenas le sangran y se desangra, que la pasión le atormenta y es tedio su esperanza.

¡Vamos, vamos!

Abandona tu cantina,

lanza al viento tu rebuzno

y en la tierra engarza tu perfume.

¡Vamos ya!

Mira al Norte y observa cómo nos acecha como un halcón en su atalaya;

óseos restos en sus garras manchadas de sangre, despojos de tan palpitantes entrañas que reclaman el quejido.

También leves plumas que bajo el ritmo implacable de su picotazo aprendieron una nueva canción. ¡Vamos!

pues los carros de ayer pasaron, no conocen el regreso. 
Los ídolos de viejas glorias que arrastrara el Tajo,

enterrados yacen en el Guadalquivir.

El grito lejano de un niño se derrama en

la plenitud del camino

y es un grito de socorro.

¡Y paloma blanca!

¡Y cueva de hambrientos!

que tu susurro resuene en la cosecha de mi

llanto,

las lágrimas laven los céfiros de mi angustia, cave una tumba para la cobardía

y entiérrala en las nubes.

Arranca el arado del tenaz espejismo

y cabalga a lomos del cielo.

Saluda, en fin, a la embrionaria mañana

pues que a ti ha venido el más valiente

blandiendo la espada del rescate.

¡Ay Sancho, mi camino!

¡Sancho, mi esperanza!

mira no te encadene la ilusión

no vayas a olvidarme.

Arrea tu jumento,

suelta al viento tu barba hirsuta,

déjala que abrace el horizonte,

que viaje a esas estrellas que murieron lejanos

techos.

Déjala revolotear como a la gaviota que picotea

conchas en el arenal de una playa.

Y que a las tumbas lleve su mensaje.

$Y$ que encienda un pabilo a las tinieblas.

Que lloriquee como el recién nacido,

pues que el llanto mostrará el camino hacia el 
seno cariñoso.

Déjala que nade en el espacio, competir con la melena del león que corre tras la presa.

Que suelta sea su brida hasta que estalle como el ritmo del timbal.

Tal vez avise los oídos de esos cuervos que duermen en lodo de pútrida carroña.

Deja que allane mi camino

y escánciame en tu vaso de barro

licor de fuego y sangre.

Que los sorbos que me ofrezca derritan el hielo en mi garganta.

Permíteme cortar una rosa de tu lanza, acaso fructifique en mis entrañas

el puñal envenenado que raspa mi sueño.

Arre tu jumento, camino mío,

abre las puertas a una difícil jornada,

deja que el rebuzno llueva sobre mi cuerpo desnudo,

competir con el viento y con los días perdidos, ser como un golpe sagrado que asestara al fuego.

¡Sancho, Sancho!

crucemos ahora el mar

y que tu ágil lengua se deslice como una balsa

y tu sonrisa de tierra como una vela se ice.

¡Adelante!

toca el mar con tu vara mágica, que yo, mi espada y mi escudo, Rocinante y yo prenderemos las espigas del viento 
y entonaremos para ti el himno de la tierra:

Así vamos, amigo mío, compañero, lamiendo la infinita planicie del mar que hierve, se algazara y se rebela.

Cual si destello de alba se tratase,

o un cementerio antiguo

o una ciudad bañada en sangre, cuyo pendón blasonase a una paloma.

Don Quijote soy, el profeta embozado, tal vez, esa tortuga que por burlar los colmillos del tigre, destuvo un instante la luz de la jungla.

Don Quijote, sí, amigo mío, que cabalgó su locura para ofrecerte el sueño de una casida.

Madrid, 20-6-1975

XVII

¿POEMA AL BURRO?

A mi amigo José María Forneas

Camina, burro,

y no te excuses.

Sé que la carga

ensangrentó tu lomo.

Lo sé.

No te menosprecies 
porque tras de ti

cargo yo la mía.

La soporto desde que la noche

se entrevera de luz,

caminando, caminando, caminando...

En las tinieblas, en el barro

¡repicando tambores

y fabricando flautas

y vainas de espada

para las fiestas!

Heme aquí corriendo sobre tus huellas, que no dejan más rastro

que el infinito camino.

$Y$ cuando volvemos la vista

se nos convierte en fantasma;

Y si lo montamos

es una cabalgada en un palo

de niño.

Lo piso

y no volveré a montarlo.

Me voy, como ves, me voy

hacia la orilla roja

donde bebo - contigo-

el llanto de los peces

y como la espuma del mar

hasta que torne la luna

de su largo viaje.

Dormiremos abrazándonos el cinturón

de la playa

y besaremos la arena.

Leeremos, a la madrugada,

palabras de sonámbulo:

un ojo 
derramando llanto

con letras silentes

dormidas sobre la seda larga

que invade el silencio.

En la enfermedad de su pobre tierra

como las hojas del otoño.

Camina, pues, burro, que la aurora asciende y deja el camino a quien lo compra...

¡Chiss, camina y calla!

\section{XVIII}

Dueño del ocaso carmesí

flotante sobre las ondas, dame tu halcón

préstame luz de tu imaginación alada

para verla y palpar su latido

y déjame surcar los campos en la tiniebla

estúpida, con los brazos abiertos

y la cabeza al aire,

llevando en mi mano tu ascua

que quizá encuentre en las torrenteras

o en las colinas eternas,

o paciendo en jugosos pastos silvestres.

Y si cantan los pájaros su sentir

percibo en el vibrar de sus trinos

un eco ascendente

hasta abrazar las nubes.

Y la veo.

Un alma sin cuerpo que traza en letras de 
plomo

en pos suyo la palabra nostalgia diciendo:

Estoy aquí, ven conmigo, si quieres...

$\mathrm{Y}$ viajo en la barca de mi fantasía

despertándome el runrún que arrulla las pobres

hojitas del otoño

y punteando en su laúd:

"Nostalgia, ¿cuándo nos uniremos, cuándo se fundirán las almas?”.

Y otra vez, y tantas veces, como siempre

la veo escrita con letras viejas

sobre la frente de quien despide,

de amanecida, al marinero

y anhelando abrazarle con el crepúsculo.

$Y$ cuando regresan, ves en sus pasos

dos palabras que saltan alborozadas

estrechándose. Eran:

"amor y nostalgia que se reencuentran

tras el abandono".

\section{XIX}

A mi amigo Rafael Rodríguez

...Compañero, amigo, aji

camarada de mi llanto;

suelta tu ardiente fulgor

sobre mi espada.

Alza tu puño feroz

Sobre mi palabra

y clama al cielo fugaz... 
...¡Qué maravilla!

Pórtate firme, bravo y muro

surca las dunas del mar sin agonía...

Ahí, verás, allí tendrás

un corazón de melodía

allí, gime un dolor que

hierve en fantasía.

...Camina burro

solo, con el sudor

en compañía.

\section{XX}

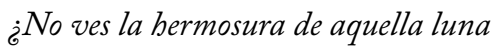

en el horizonte?

Parece una corona, tal vez arco iris, una barca, a una letra de Nun escrita con lima de oro sobre un cristal azul

Abu-1-Baqà de Ronda, s. XIV.

Siempre navegando por el camino:

desde los confines del Hoggar, un vasto

pasto

de arenal me guía;

¡lamiendo el céfiro de un latido sereno!

Un río de cristal se vierte

hacia el infinito

En la otra orilla, dos siluetas de verde

clamor suplican el horizonte.

¡Qué claro deleite se ve vagar

persiguiendo la sombra de una caravana 
de zureo y velos de un atardecer herido!

Te llevo como a los suspiros intercostales, te llevo pese a las mareas de verde oleaje.

Ya no siento vacío

ni con cristal roto en la frente;

sólo gacelas de nocturnas miradas

$\mathrm{y}$ de panal de sonrisas.

Deja fundir tu sombra en el asfalto

del descubrimiento...

En las vidrieras congeladas, de un Museo

sombrío

iitus huesos de ayer se besan con faroles!! 
Glosario:

'Abayya: Túnica árabe

Abu-1-Hayyay: Yusuf I, rey de Granada (1333-1354).

Aures: Montañas en el noreste de Argelia donde se declaró la revolución de 1954.

\section{Aji: Hermano}

Banu al-Ahmar: Dinastía de los reyes nazaríes de Granada $(1232-1492)$

Casida: Poema monorrimo árabe

Constantina: Ciudad en el noreste de Argelia.

Halcón de Qurays: Calificativo con el que se conocía a Abderramán $\mathrm{I}$.

Hoggar: Región de los hombres azules llamados Tuareg.

Ibn al-Jatib: Gran visir de Granada y poeta (1313-1375).

Sinhaya: Tribu beréber.

Zinatí: Apellido beréber, de donde viene “jinete”. 